\title{
Экспертиза
}

НАЗАРОВА Наталья Александровна - кандидат экономических наук, доцент департамента политологии и массовых коммуникаций Финансового университета при Правительстве РФ(125993, Россия, г. Москва, Ленинградский пр-кт, 49, паanazarova@fa.ru)

\section{ГОСУДАРСТВЕННАЯ ПОЛИТИКА СТИМУЛИРОВАНИЯ ПРЕДПРИНИМАТЕЛЬСКОЙ ДЕЯТЕЛЬНОСТИ В РОССИЙСКИХ РЕГИОНАХ}

\begin{abstract}
Аннотация. В статье рассматриваются основные проблемы в области поддержки предпринимательства, стоящие перед российским правительством и региональной властью, а также возможные пути их преодоления. Автор обосновывает целесообразность разработки системы региональной политики стимулирования предпринимательской деятельности в отношении действующих компаний, ориентированных на развитие и имеющих к этому потенциал, а также описывает принципы, задачи и методы построения региональной системы акселерации малого и среднего предпринимательства.

Ключевые слова: политика стимулирования предпринимательства, малое и среднее предпринимательство, акселерация предпринимательской деятельности, региональное предпринимательство, предпринимательская активность, взаимодействие бизнеса и власти
\end{abstract}

$\Gamma$ осударственная политика в области развития малого и среднего предпринимательства является важной частью государственной социально-экономической политики любой страны. Развитие предпринимательства влияет на экономический рост за счет повышения маневренности экономики, влияния на ее инновационный потенциал, эффекта выравнивания экономического развития отдельных территорий внутри страны.

Значением государственной политики в стимулировании предпринимательской активности занимались такие исследователи, как Д.Дж. Стори, Дж.Г. Спенсер, С. Госем, А.Ю. Чепуренко и др. Признанными сторонниками институционального фактора в сфере развития предпринимательства являются Д. Норт, У.Дж. Баумоль, Н.З. Солодилова, Р.И. Маликов, К.Е. Гришин. Региональные аспекты развития малого и среднего бизнеса изучали в своих работах А. Баранов, Е. Малков, Л. Полищук, М. Рохлиц, Г. Сюняев [Баранов и др. 2015], С.П. Земцов, Ю.В. Царева.

В указе «О национальных целях и стратегических задачах развития Российской Федерации на период до 2024 года» от 7 мая 2018 г. президент РФ обозначил задачу создать систему акселерации субъектов малого и среднего предпринимательства, включая индивидуальных предпринимателей, в т.ч. структуру и сервисы поддержки, а также обеспечить их ускоренное развитие в таких областях, как благоустройство городской среды, научно-технологическая сфера, социальная сфера и экология.

Сегодня ситуация выглядит следующим образом: в Российской Федерации существуют около 6 млн хозяйствующих субъектов, которые дают рабочие места 19,2 млн граждан. Вместе с тем в стране создан организационный и нормативно-правовой плацдарм по поддержке и развитию малого и среднего бизнеса ${ }^{1}$. Также реализуется ряд масштабных мер финансовой, имущественной и информационно-консультационной поддержки и развития малого и среднего предпринимательства.

Однако показатели МСП в значительной степени низки в сравнении не

1 Стратегия развития малого и среднего предпринимательства в Российской Федерации на период до 2030 года, Утв. расп. Правительства РФ от 02.06.2016 № 1083-p. Доступ: http://pravo.gov.ru/proxy/ ips/?docbody=\&nd=102400738 (проверено 19.03.2019). 
только с большинством развитых, но и развивающихся стран: доля малого и среднего предпринимательства в ВВП - 22,3\%. Поставлена цель достигнуть к 2024 г. уровня в $32 \% 1$.

95,5\% общего числа МСП - это микробизнес (на апрель 2019 г. 5,8 млн составляют микропредприятия, 250000 - малые компании, 18500 - средний бизнес 2 ). Следует отметить низкое число средних предприятий. На это стоит обратить особое внимание, поскольку в качественном соотношении структура малого и среднего бизнеса в России ухудшается - число малых и средних предприятий имеет тенденцию к стремительному снижению. Реальный рост заметен лишь в структуре микробизнеса. Такая ситуация разительно отличается от состояния МСП в зарубежных странах. Например, в Канаде ${ }^{3}$ по состоянию на декабрь 2015 г. доля микробизнеса в общем числе МСП составляет 54,1\% (43\% малых предприятий, $1,8 \%$ - средних), а в Великобритании - 81,5\% (15,5\% малых предприятий, 2,5\% - средних $)^{4}$.

42,7\% МСП действуют в сфере торговли (структура МСП по видам экономической деятельности практически не меняется).

Отсюда можно прийти к следующему заключению: малое и среднее предпринимательство в России находится в процессе перехода от начального этапа зарождения к этапу развития, в основе которого лежат устойчивость и эффективность предприятий, активизация бизнес-процессов и улучшение их инновационной и производственной деятельности, ориентация на масштабирование и экспорт. Кроме того, основные показатели состояния малого и среднего предпринимательства в РФ говорят о необходимости изменения его отраслевой структуры.

Для решения поставленных задач в рамках обеспечения устойчивых темпов экономического роста существует запрос на создание механизма «доращивания» предприятий до их следующего уровня развития.

Что касается развития бизнеса, то существуют 5 этапов жизненного цикла деятельности предпринимателя. Это крайне важно учитывать при разработке концепции взаимодействия власти и бизнеса.

Этапы деятельности выглядят следующим образом: 1) вовлечение, 2) создание бизнеса, 3) развитие бизнеса, 4) масштабирование и выход на новые рынки, 5) инвестирование в новые направления [Назарова 2018: 153].

Под системой акселерации субъектов малого и среднего бизнеса предлагаем понимать систему поддержки предприятий, которая заключается в стимулировании и обеспечении интенсивного ускоренного роста, основанного на развитии масштабов предприятий, внедрении новых технологий и новых продуктов, выходе на новые рынки. Соответственно, федеральный проект с одноименным названием призван сконцентрировать силы на увеличении числа и качества предприятий, способных на рост в рамках третьего (развитие бизнеса) и четвертого (масштабирование) жизненных циклов.

Автор статьи провел экспертное интервью, в котором приняли участие 30 представителей институтов поддержки бизнеса из Москвы, Вологодской,

\footnotetext{
${ }^{1}$ Паспорт национального проекта «Малое и среднее предпринимательство и поддержка индивидуальной предпринимательской инициативы». 24 декабря 2016 г. Доступ: http://static.government.ru/ media/files/qH8voRLuhAVWSJhIS8XYbZBsAvcs8A5t.pdf (проверено 19.03.2019).

2 Единый реестр субъектов малого и среднего предпринимательства. - Федеральная налоговая служба. Доступ: https://rmsp.nalog.ru/statistics.html (проверено 02.04.2019).

3 SMEs and Entrepreneurship Policy in Canada. Paris: OECD Publishing. URL: http://dx.doi. org/10.1787/9789264273467-en (accessed 19.03.2019).

4 United Kingdom. Financing SMEs and Entrepreneurs 2017. An OECD Scoreboard. Paris: OECD Publishing. URL: http://dx.doi.org/10.1787/fin_sme_ent-2017-48-en (accessed 19.03.2019).
} 
Нижегородской, Пензенской, Псковской, Ульяновской обл., Республики Марий Эл.

Эксперты отмечали низкую готовность российского бизнеса к выходу на международные рынки и расширению своего бизнеса.

1. Наблюдается низкая мотивация действующего бизнеса к расширению масштабов компаний. Данное мнение также подтверждается данными национального отчета в рамках реализации проекта «Глобальный мониторинг предпринимательства»:

- 76\% респондентов из устоявшихся предпринимателей не используют в своем деле новейшие и новые технологии;

- 77\% респондентов из устоявшихся предпринимателей не имеют планов по рыночной экспансии в обозримой перспективе [Верховская, Дорохина, Сергеева 2014: 38].

Кроме того, в рейтинге Doing Business по критерию «Международная торговля» Россия находится на 99-м месте (между ОАЭ и Вьетнамом) ${ }^{1}$.

2. Предприниматели, которые развивают свой бизнес в новых направлениях, часто не видят структуру рынка. Они оказываются не способными определить актуальные отрасли, в которых существует динамичный потенциал развития. Также предприниматели часто повторяют те виды бизнеса, которые уже существуют на рынке: такие проекты нередко оказываются совершенно неактуальными.

3. Рамки выхода на высокоуровневые рынки сбыта (оптовые поставки или федеральные сети) требуют от бизнесмена огромных объемов поставок, развитой логистики и стандартов качества. Такие условия предприниматель не способен обеспечить в одиночку.

4. Для перехода на этап масштабирования бизнеса и выхода на новые рынки предпринимателям недостаточно знаний, управленческих компетенций, качества команд и стратегического видения.

5. Бизнес предпочитает вкладываться в пассивный доход.

Для решения вопросов масштабирования существующих предприятий и их ориентации на экспорт предусмотрены меры, которые ориентированы на улучшение доступа к рынкам сбыта для малого и среднего бизнеса и кредитным ресурсам. При этом эксперты обозначают, что реализация вышеперечисленных мер требует поддержки региональной власти [Баринова, Земцов, Царева 2018: 92] с применением методологии проектного подхода, включающей:

- создание четкой и разделяемой бизнесом социально-экономической стратегии развития региона;

- фокусирование мер и инструментов поддержки организаций, которые обладают реальным потенциалом качественного развития и имеют амбиции долгосрочного роста;

- выработку индивидуальных траекторий развития предприятий и организаций, а также набора комплексных решений в зависимости от уровня их жизненных циклов и актуальных рыночных факторов;

- использование метода «умной специализации» при выборе региональных видов бизнеса для их акселерации;

- ориентированность на включение быстрорастущих компаний в производственную цепь региональных секторов и кластеров промышленности для последующей реализации «вытягивающего» эффекта для иных секторов и предприятий экономики субъекта РФ.

\footnotetext{
${ }^{1}$ Рейтинг стран. Всемирный банк МБРР - МАР. - Doing Business. Май 2018 г. Доступ: http://russian. doingbusiness.org/ru/rankings (проверено 19.03.2019).
} 
Региональная система акселерации бизнеса должна выполнять в работе с компаниями следующие функции:

- анализировать быстрорастущие компании региона, которые обладают высоким потенциалом для последующего роста и амбициями долгосрочного развития;

- вовлекать компании в акселерацию посредством обеспечения их конструктивного диалога с властью в заданном регионе;

- выявлять сдерживающие факторы развития бизнеса и искать решения по данным вопросам;

- обеспечивать условия для эффективного исполнения выработанных решений.

Для того чтобы реализовать данные условия, необходимо сформировать у региональных предпринимателей новую культуру ведения бизнеса. Такая культура должна основываться на принципах открытости, прозрачности работы, кооперации, перспективного видения, создания системы кадрового обеспечения развития компаний в регионе, обеспечения роста компаний инвестиционными и кредитными ресурсами, а также на осуществлении поддержки выхода компаний на новые рынки с формированием устойчивых каналов сбыта. Рассмотрению влияния данных факторов уделено внимание в работе М. Босмы и В. Щутенса, а также в исследовании С. Джанкова.

Основными задачами в процессе акселерации малого и среднего предпринимательства в регионах являются:

- помощь в усовершенствовании профессиональных сервисных компаний, итогом которой будет являться привлечение инвестиций, а также человеческого капитала в сферы маркетинга, финансового консалтинга, бизнес-образования, бухгалтерского сопровождения и юриспруденции;

- предоставление единого пакета услуг для организации финансирования по регионам;

- развитие вектора технологического направления в консалтинге (подбор технологий и оборудования, разработка новых мощностей) в условиях особой актуальности цифровой экономики - экономики будущего;

- создание и предоставление условий, которые способствуют кооперации и осуществлению кластерного подхода для выхода предпринимателей на новые рынки (федерального или международного масштаба), ресурсному бартеру, взаимообмену оборудованием, людьми или идеями в условиях построения конструктивных взаимоотношений бизнеса, власти, науки региона, а также проработка бизнес-моделей кооперационных проектов (их юридической, сервисной и логистической составляющих);

- создание среды, которая бы мотивировала предпринимателей к выходу на новые уровни развития (нацеленность на федеральные и международные рынки) и на активное взаимодействие с предпринимательскими объединениями;

- стимулирование кооперации региональных организаций развития и поддержки малого и среднего предпринимательства между собой и с внутренними структурами, которые действуют в области оказания услуг предпринимателям (бизнес-объединения, банки, сервисные компании и др.) для усиления согласованности уровня эффективности учета и использования ресурсов; использование принципа ГЧП;

- создание и совершенствование стратегических отраслевых объектов тех или иных регионов в рамках привлечения внимания к взаимодействию предпринимателей, которые имеют серьезный потенциал роста бизнеса (по экспоненте), и инвесторов с прямыми инвестициями. 
Таким образом, можно отметить, что сегодня в системе стимулирования, развития и усовершенствования предпринимательской деятельности уделяется недостаточно внимания предпринимателям, которые уже проверили себя правилами рынка и устоялись на нем, но остановились в своем развитии, направив существующие финансовые ресурсы на вложения непредпринимательского характера. При этом стоит отметить, что на региональном уровне решение данного ряда задач возможно лишь на основе выстраивания здоровых взаимоотношений бизнеса и власти, которые были бы основаны на выработке общих интересов, связанных с привлечением инвестиций и региональным развитием [Расторгуев, Хализова 2015: 50]. Реализация такого сценария требует согласованности действий бизнес-структур и региональных органов власти.

\section{Список литературы}

Баранов А., Малков Е., Полищук Л., Рохлиц М., Сюняев Г. 2015. Измерение институтов в российских регионах: методология, источники данных, анализ. Вопросы экономики. № 2. С. 69-103.

Баринова В.А., Земцов С.П., Царева Ю.В. 2018. Предпринимательство и институты: есть ли связь на региональном уровне в России? - Bonpocы экономики. № 6. С. 92-116.

Верховская О.Р., Дорохина М.В., Сергеева А.В. 2014. Глобальный мониторинг предпринимательства: национальный отчет. Россия 2013. СПб. 64 с. Доступ: https://gsom.spbu.ru/images/cms/data/faculty/gem_2013_final20_all.pdf (проверено 04.05.2019).

Назарова Н.А. 2018. Актуальные проблемы стимулирования предпринимательства в российских регионах и принципы взаимодействия с органами власти (GR) для частных компаний. - Технологии и компетенции PR u GR в условиях uифровой экономики: монография (под ред. С.Ю. Белоконева, 3.Р. Усмановой). М.: КноРус.

Расторгуев С.В., Хализова В.Д. 2015. Государственно-частное партнерство в современной России: игра с взаимным выигрышем или с нулевой суммой? Власть. № 10. С. 50-55.

NAZAROVA Natal'ya Aleksandrovna, Cand.Sci. (Econ.), Associate Professor of the Department of Political Science and Mass Communications, Financial University under the Government of the Russian Federation (49 Leningradsky Ave, Moscow, GSP-3, Russia, 125993; naanazarova@fa.ru)

\section{STATE POLICY OF STIMULATING BUSINESS ACTIVITIES IN RUSSIAN REGIONS}

\footnotetext{
Abstract. The article discusses the main problems of the Russian government and regional authorities towards supporting entrepreneurship, and lists possible ways to overcome them. The author justifies the feasibility of developing a system of regional business incentive policies for existing development-oriented companies with potential for this, and describes the principles, tasks and methods of building a regional acceleration system for small and medium-sized businesses.

Keywords: business promotion policy, small and medium-sized business, acceleration of business activities, regional entrepreneurship, entrepreneurial activity, interaction between business and government
} 